\title{
Gargling Method of Administration
}

National Cancer Institute

\section{Source}

National Cancer Institute. Gargling Method of Administration. NCI Thesaurus. Code C149523.

The technique of administration of a pharmaceutical product by rinsing the throat and/or mouth with it, holding it in the throat and keeping it in motion by releasing a stream of air from the lungs; after gargling, the product is usually intended to be spat out. 